\title{
Biochemical basis of cancer chemoprevention and/or chemotherapy with ginsenosides (Review)
}

\author{
JOON-SEOK CHOI $^{1 *}, \mathrm{KYUNG} \mathrm{KOO} \mathrm{CHUN}^{2 *}, \mathrm{JUTHIKA} \mathrm{KUNDU}^{2}$ and JOYDEB KUMAR KUNDU ${ }^{2}$ \\ ${ }^{1}$ College of Life Sciences and Biotechnology, Korea University, Seoul 136-701; \\ ${ }^{2}$ College of Pharmacy, Keimyung University, Daegu 704-701, Republic of Korea
}

Received July 9, 2013; Accepted September 26, 2013

DOI: $10.3892 /$ ijmm.2013.1519

\begin{abstract}
Cancer still imposes a global threat to public health. After decades of research on cancer biology and enormous efforts in developing anticancer therapies, we now understand that the majority of cancers can be prevented. Bioactive phytochemicals present in edible plants have been shown to reduce the risk of various types of cancer. Ginseng (Panax ginseng C.A. Meyer), which contains a wide variety of saponins, known as ginsenosides, is an age-old remedy for human ailments, including cancer. Numerous laboratory-based studies have revealed the anticancer properties of ginsenosides, which compel tumor cells to commit suicide, arrest the proliferation of cancer cells in culture and inhibit experimentally-induced tumor formation in laboratory animals. Ginsenosides have been reported to inhibit tumor angiogenesis, as well as the invasion and metastasis of various types of cancer cells. Moreover, ginsenosides as combination therapy enhance the sensitivity of chemoresistant tumors to clinically used chemotherapeutic agents. This review sheds light on the molecular mechanisms underlying the cancer chemopreventive and/or chemotherapeutic activity of ginsenosides and their intestinal metabolites with particular focus on the modulation of cell signaling pathways associated with oxidative stress, inflammation, cell proliferation, apoptosis, angiogenesis and the metastasis of cancer cells.
\end{abstract}

\section{Contents}

1. Ginsenosides: the ginseng saponins

2. Ginsenosides in the prevention and therapy of cancer

Correspondence to: Dr Joydeb Kumar Kundu, College of Pharmacy, Keimyung University, 2800 Dalgubeodaero, Dalseo-gu, Daegu 704-701, Republic of Korea

E-mail:kundujk@yahoo.com; kundujk@kmu.ac.kr

*Contributed equally

Key words: ginsenosides, chemoprevention, chemosensitization, cell signaling
3. Biochemical basis of anticancer properties of selected ginsenosides

4. Future perspectives

\section{Ginsenosides: the ginseng saponins}

Ginseng (Panax ginseng C.A. Meyer) is widely used as a component of oriental medicine in different countries worldwide, including South Korea and China. The medicinal use of ginseng dates back 2,000 years. Scientific approaches for the chemical characterization of ginseng began when Garriques isolated a type of saponin mixture, and named it panaquilon in 1854 . At the dawn of the 20th century, a group of scholars took the initiative to isolate saponin components from the mixture. It was the Russian pharmacologist, Brekhman, who first demonstrated that saponins may be the active ingredients which exert the pharmacological effects of ginseng (1). Brekhman's report was further confirmed when a wide variety of biologically active ginseng saponins with variable molecular weights ranging between 800-1,200 were isolated in subsequent years (2).

Saponins are a group of compounds consisting of a sugar moiety (glycone) and a non-sugar component (aglycone) connected by ether linkage. Based on the structures of the aglycone, saponins are classified as triterpenoid saponins and steroid saponins. Triterpenoid saponins obtained from ginseng can be further classified as tetracyclic dammarane-type saponins and pentacyclic oleane-type saponins. Depending on the number of hydroxyl groups present in the aglycone component, dammarane saponins can again be classified into two types: protopanaxadiol and protopanaxatriol saponins. According to the manufacturing process, ginseng can be grouped as red or white ginseng. Amazingly, there are apparent differences in the composition of ginseng saponins between the red and white varieties. The red ginseng-specific saponins are produced by heat processing of the Korean ginseng source $(3,4)$. The isolation and quality assessment of ginseng saponins are usually carried out using thin layer chromatography (TLC). The Rf values, the ratio of the distance travelled by saponins to that of the solvent, in the TLC chromatogram is used to identify an individual saponin. The nomenclature of ginseng saponins is given by a general term 'ginsenoside-Rx', where ' $\mathrm{R}$ ' stands for the root or radix, and $\mathrm{x}$ is replaced with an alphabet from a to $h$, which specifies $R f$ values in an ascending order. 
Since the structure of ginsenoside Rg1 from the mixture of ginseng saponins has been reported in 1971, >30 ginsenosides have been found in the roots and other parts of Panax ginseng, and a total of $>60$ ginsenosides have been isolated from members of the Panax genus. Chemical structures of several common ginsenosides are presented in Fig. 1. The substituents (R1, R2 and R3) in Fig. 1A for selected ginsenosides are listed in Table I. In general, the ginseng saponins can be divided according to the structure of the aglycone component of the molecule: i) the oleanolic acid type, such as ginsenoside $\mathrm{R}_{0}$; ii) the 20(S)-protopanaxadiol type, such as ginsenosides $\mathrm{Ra}, \mathrm{Rb}$, Rc, Rd, Rg3, Rh2 and Rs; and iii) the 20(S)-protopanaxatriol type, such as ginsenosides $\mathrm{Re}, \mathrm{Rf}, \mathrm{Rg} 1, \mathrm{Rg} 2$ and $\mathrm{Rh} 1(2,5,6)$. The detailed chemistry and the structure-activity relationship of diverse classes of ginsenosides have been reviewed elsewhere (6-8) and is beyond the scope this article. The aim of this review was limited to the biochemistry behind the anticancer activity of ginsenosides.

\section{Ginsenosides in the prevention and therapy of cancer}

The anticancer properties of ginsenosides have been extensively investigated over the past several decades. Ginsenosides have been shown to elicit chemopreventive and chemotherapeutic effects in a wide range of animal models of experimental carcinogenesis (5,8-10) (Table II). For instance, the topical application of $\operatorname{Rg} 3$ on to the shaven backs of female ICR mice has been shown to inhibit 12-O-tetradecanoylphorbol-13acetate (TPA)-induced ornithine decarboxylase activity and 7,12-dimethylbenz[a]anthracene (DMBA)-initiated papilloma formation (11). Likewise, the oral administration of ginsenoside Rp1 at the pre-, peri- and post-initiation stage, has been shown to significantly reduce the incidence and the multiplicity of chemically-induced mouse skin papillomas (12). As previously demonstrated, the water extract of Korean red ginseng attenuated the development of testosterone-induced benign prostate hyperplasia, a pre-neoplastic condition that progresses to malignant prostate cancer (13).

The inhibitory effects of various ginsenosides on the growth of different cancer cell xenograft tumors have been reported. For example, treatment with $\operatorname{Rg} 3$ has been shown to inhibit the growth of human colon cancer (HCT-116) cell xenograft tumors in nude mice (14). The administration of $\mathrm{Rg} 3$ alone or in combination with gemcitabine, has also significantly inhibited the growth of Lewis lung carcinoma cells implanted into C57BL/6 mice by suppressing tumor angiogenesis (15). The oral administration of $\mathrm{Rh} 2$ has been shown to reduce human prostate cancer (PC3) cell tumor growth in nude mice (16). Likewise, as previously demonstrated, the growth of human gastric cancer (SGC7901) cells in nude mice was diminished by compound $\mathrm{K}$, an intestinal metabolite of ginsenoside $\mathrm{Rb1}$, $\mathrm{Rb} 2$ and $\mathrm{Rc}$ (17). A previous study revealed that 25-methoxyprotopanaxadoil reduced the growth of human lung cancer (A549) cell tumor xenografts in nude mice (18). Similarly, 25-methoxy-protopanaxadiol and 25-hydroxy-protopanaxadiol have been shown to inhibit pancreatic cancer cell xenograft tumor growth in vivo and to reduce the proliferative abitlity of these cells in vitro (19). Treatment with 20(S)-25-methoxyldammarane-3 $\beta, 12 \beta, 20$-triol, a newly identified ginsenoside from Panax notoginseng, has been shown to decrease the
Table I. List of substituents (R1, R2 and R3) shown in Fig. 1A for selected ginsenosides.

\begin{tabular}{|c|c|c|c|}
\hline Ginsenosides & R1 & $\mathrm{R} 2$ & R3 \\
\hline Ra1 & Glc-Glc- & $\mathrm{H}$ & Xyl-Ara(f)-Glc- \\
\hline $\mathrm{Ra} 2$ & Glc-Glc- & $\mathrm{H}$ & Xyl-Ara(f)-Glc- \\
\hline $\mathrm{Rb} 1$ & Glc-Glc- & $\mathrm{H}$ & Glc-Glc- \\
\hline $\mathrm{Rb} 2$ & Glc-Glc- & $\mathrm{H}$ & Ara(p)-Glc- \\
\hline $\mathrm{Rc}$ & Glc-Glc- & $\mathrm{H}$ & Ara(f)-Glc- \\
\hline $\mathrm{Rd}$ & Glc-Glc- & $\mathrm{H}$ & Glc- \\
\hline $\mathrm{Re}$ & $\mathrm{H}$ & Rha-Glc-O- & Glc- \\
\hline Rf & $\mathrm{H}$ & Glc-Glc-O- & $\mathrm{H}$ \\
\hline $\operatorname{Rg} 1$ & $\mathrm{H}$ & Glc-O- & Glc- \\
\hline $\operatorname{Rg} 2$ & $\mathrm{H}$ & Rha-Glc-O- & $\mathrm{H}$ \\
\hline $\operatorname{Rg} 3$ & Glc-Glc- & $\mathrm{H}$ & $\mathrm{H}$ \\
\hline Rh1 & $\mathrm{H}$ & Glc-O- & $\mathrm{H}$ \\
\hline $\mathrm{Rh} 2$ & Glc- & $\mathrm{H}$ & $\mathrm{H}$ \\
\hline Rp1 & Glc-Glc- & $\mathrm{H}$ & $\mathrm{H}$ \\
\hline Rs3 & AcGlu-Glu- & $\mathrm{H}$ & $\mathrm{H}$ \\
\hline Compound K & $\mathrm{H}$ & $\mathrm{H}$ & Glc- \\
\hline
\end{tabular}

Glc, glucopyranoside; Ara(f), arabinofuranose; Ara(p), arabinopyranoside; Rha, rhamnopyranoside.

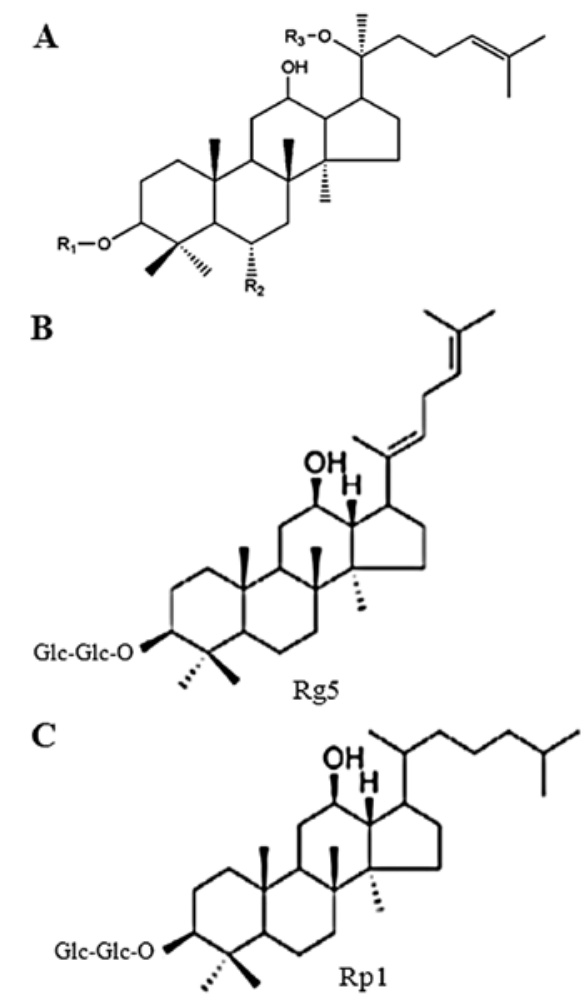

Figure 1. Chemical structures of ginsenosides. (A) General structure of ginsenosides. The substituents R1, R2 and R3 are defined in Table I. Chemical structure of (B) Rg5 and (C) Rp1.

growth of human breast cancer (MCF-7 and MDA-MB-231) cell tumor xenografts in nude mice (20). As previously shown, 
Table II. Inhibitory effects of ginsenosides on the development and growth of tumors in vivo.

\begin{tabular}{|c|c|c|c|}
\hline Ginsenosides & Animal model & Mechanisms/effects & Refs. \\
\hline Rp1 & $\begin{array}{l}\text { DMBA-initiated and croton oil-promoted } \\
\text { skin papillomagenesis in Swiss albino mice }\end{array}$ & $\begin{array}{l}\downarrow \text { Tumor incidence and multiplicity } \\
\downarrow \text { Lipid peroxidation } \\
\uparrow \text { Activity of microsomal enzymes } \\
\uparrow \text { Activity of SOD, GPx, GR and GST } \\
\uparrow \text { Level of reduced glutathione }\end{array}$ & $(12)$ \\
\hline $\operatorname{Rg} 3$ & $\begin{array}{l}\text { DMBA-initiated and TPA-promoted skin } \\
\text { papillomagenesis in female ICR mice }\end{array}$ & $\begin{array}{l}\downarrow \text { Average number of skin tumors } \\
\downarrow \text { Orinithine decarboxylase activity } \\
\downarrow \text { Expression of COX-2 } \\
\downarrow \text { Activation of NF- } \mathrm{KB} \text { and AP-1 }\end{array}$ & $(11)$ \\
\hline $\operatorname{Rg} 3$ & HCT-116 cells xenograft tumor in nude mice & $\begin{array}{l}\downarrow \text { Xenograft tumor growth } \\
\downarrow \text { Expression of PCNA } \\
\downarrow \text { Nuclear staining of } \beta \text {-catenin } \\
\downarrow \beta \text {-catenin/TCF-mediated } \\
\quad \text { transcriptional activity }\end{array}$ & $(14)$ \\
\hline $\begin{array}{l}\text { Rg3 alone or } \\
\text { with gemcitabine }\end{array}$ & $\begin{array}{l}\text { Lewis lung cancer xenografts in syngenic } \\
\text { C57BL/6 mice }\end{array}$ & $\begin{array}{l}\downarrow \text { Tumor growth } \\
\downarrow \text { VEGF expression } \\
\uparrow \text { Survival of tumor-bearing mice }\end{array}$ & $(15)$ \\
\hline $\operatorname{Rg} 3$ & $\begin{array}{l}\text { Administration of SKOV-3 cells via lateral } \\
\text { tail vein and intraperitoneal administration } \\
\text { of Rg3 daily for } 20 \text { days from the day of } \\
\text { tumor inoculation. } \\
\text { Intradermal injection of SKOV-3 cells to mice } \\
\text { and treatment with } \mathrm{Rg} 3 \text { daily for five days after } \\
\text { tumor inoculation }\end{array}$ & $\begin{array}{l}\downarrow \text { Tumor angiogenesis in SKOV-3 } \\
\text { cell xenograft tumors }\end{array}$ & $(80)$ \\
\hline $\begin{array}{l}\mathrm{Rg} 3 \text { alone or with } \\
\text { cyclophosphamide }\end{array}$ & $\begin{array}{l}\text { Human ovarian cancer cell xenografts } \\
\text { in nude mice }\end{array}$ & $\begin{array}{l}\downarrow \text { Tumor growth } \\
\downarrow \text { Expression of PCNA and VEGF } \\
\downarrow \text { Microvessel density }\end{array}$ & $(73)$ \\
\hline $\begin{array}{l}\text { Water extract } \\
\text { containing } 20(\mathrm{~s})-\operatorname{Rg} 3\end{array}$ & $\begin{array}{l}\text { Testosterone-induced benign prostate hyperplasia } \\
\text { in rats and prostate cell growth }\end{array}$ & $\begin{array}{l}\downarrow \text { Thickening of prostate epithelium } \\
\downarrow \text { AR activity } \\
\downarrow \text { Proliferation of prostate cells }\end{array}$ & (13) \\
\hline $\mathrm{Rb} 2$ & $\begin{array}{l}\text { B16-BL6 melanoma xenograft tumor in nude } \\
\text { mice (intratumoral or oral administration of Rb2) }\end{array}$ & $\downarrow$ Tumor angiogenesis and growth & $(76)$ \\
\hline $\mathrm{Rh} 2$ & $\begin{array}{l}\text { MDA-MB-231 cell xenografts in nude mice } \\
\text { (Rh2 given by oral gavage) }\end{array}$ & $\begin{array}{l}\downarrow \text { Tumor growth, } \\
\uparrow \text { Intratumoral apoptotic bodies } \\
\downarrow \text { Proliferation index }\end{array}$ & $(46)$ \\
\hline M1 & Lewis lung carcinoma in syngenic C57BL/6 mice & $\downarrow$ Lung metastasis & $(88)$ \\
\hline Compound $\mathrm{K}$ & $\begin{array}{l}\text { Gastric cancer (SGC7901) cell tumor } \\
\text { xenografts in athymic nude mice }\end{array}$ & $\begin{array}{l}\downarrow \text { Tumor volume and weight } \\
\downarrow \text { Expression of Bid and MMP-9 } \\
\text { in xenograft tumors and in liver }\end{array}$ & $(17)$ \\
\hline
\end{tabular}

DMBA, 7,12-dimethylbenz[a]anthracene; TPA, 12-O-tetradecanoylphorbol-13-acetate; SOD, superoxide dismutase; GPx, glutathione peroxidase; GR, glutathione reductase; GST, glutathione-S-transferase; COX-2, cyclooxygenase-2; NF- $\kappa \mathrm{B}$, nuclear factor- $\kappa \mathrm{B}$; PCNA, proliferating cell nuclear antigen; VEGF, vascular endothelial growth factor; AR, androgen receptor.

25-hydroxy-protopanaxadiol, but not 25-hydroxy-protopanaxatriol, inhibited PC3 cell xenograft tumor growth (21).

Over the past several decades, enormous efforts have been made to elucidate the biochemistry behind the anticancer properties of various ginsenosides. The major mechanisms of the anticarcinogenic effects of ginsenosides include: i) the inhibition of oxidative damage and inflammation; ii) the inhibition of tumor cell proliferation; iii) the induction of cancer 


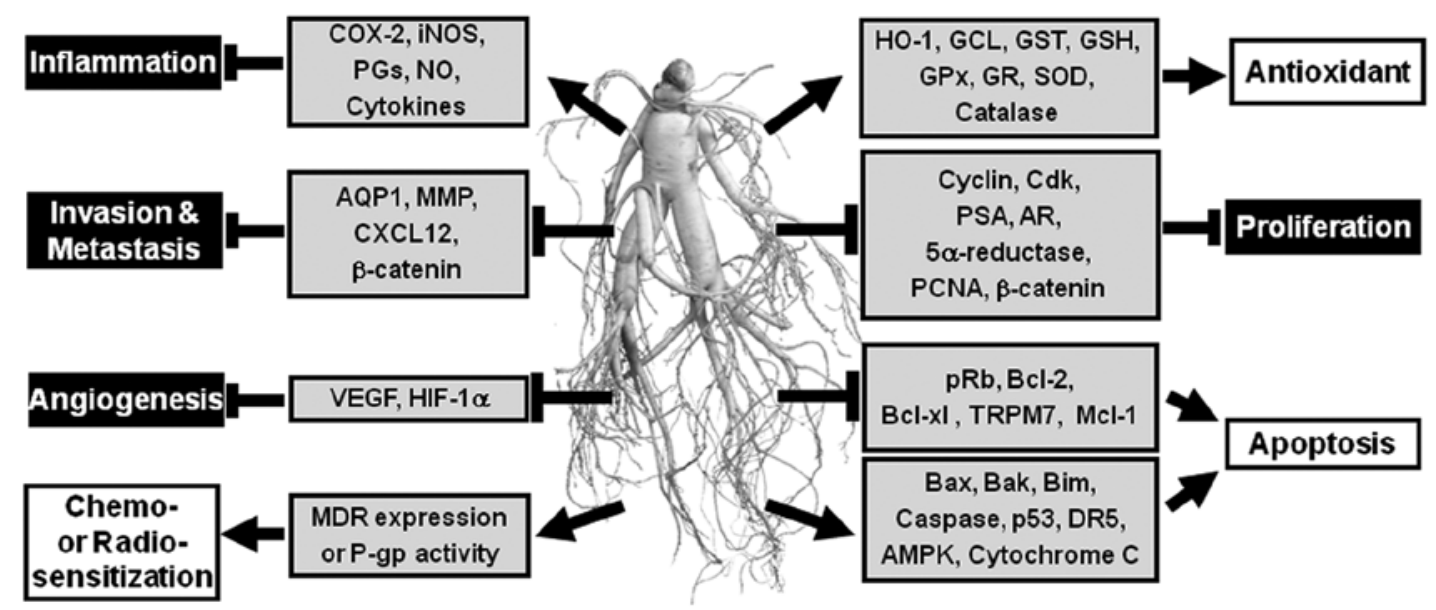

Figure 2. Schematic diagram showing common molecular targets of ginsenosides. Although a wide variety of ginsenosides have a broad range of molecular targets, a generalization of molecular targets can be made as depicted herein. Common mechanisms of anticancer activity of ginsenosides include cell cycle arrest and the induction of apoptosis in cancer cells. Thus, cell cycle regulatory proteins and apoptosis-related proteins are the common molecular targets of structurally diverse classes of ginsenosides. In addition, molecular markers of oxidative stress and inflammation, tumor angiogenesis and invasion are the targets of ginsenosides. The image of ginseng was provided by the Korea Ginseng Corp., Daejeon, Korea.

cell apoptosis; iv) anti-angiogenic activity; v) inhibition of the invasion and metastasis of tumor cells; and vi) the enhancement of the sensitivity of resistant cells to chemotherapeutic agents (Fig. 2).

\section{Biochemical basis of anticancer properties of selected ginsenosides}

Antioxidant activity. The oxidative stress-induced damage of cellular macromolecules, such as proteins, nucleic acids and lipids contributes to the neoplastic transformation of cells. Whereas oxidative stress-induced tissue damage precipitates a state of local tissue inflammation, persistent inflammation triggers the generation of reactive oxygen species (ROS) and reactive nitrogen species. A wide variety of antioxidant and anti-inflammatory phytochemicals have been reported to possess anticancer properties. Although it is generally accepted that the bioactivity of ginsenosides is due to their ability to reduce oxidative stress and inflammation, there have been limited studies unraveling the molecular mechanisms of the antioxidant and anti-inflammatory activity of individual ginsenosides. In general, ginsenosides scavenge ROS and induce the expression and activity of various antioxidant and/or detoxification enzymes. For instance, Rb1 has been reported to protect plasmid DNA from damage by the direct scavenging of $\cdot \mathrm{OH}$, which can bind to the double bond on the side chain of Rb1, as well as hydrogen atoms adjacent to the $\mathrm{OH}$ group, including those of sugar moieties. Rb1 has also elicited high reactivity to hypochlorous acid ( $\mathrm{HOCl})$, a neutrophilic oxidant with mutagenic potential, effectively inhibiting $\mathrm{HOCl}$-induced tyrosine chlorination in a cell free system (22). Ginsenosides Rg3 and $\mathrm{Rh} 2$ have been shown to reduce the ethanol-induced generation of ROS in mouse hepatocyte cells (23).

Ginsenosides have been reported to activate several antioxidant enzymes, which are transcriptionally regulated to a great extent by factors, such as nuclear factor erythroid-derived 2-like 2 (Nrf2), nuclear factor- $\kappa \mathrm{B}(\mathrm{NF}-\kappa \mathrm{B})$, or activator protein
(AP)-1 or -2. As peviously demonstrated, 20(s)-protopanaxadiol, but not total saponins or 20(s)-protopanaxatriol, induced the expression of superoxide dismutase (SOD), possibly by increasing the AP2 transcription factor activity (24). Among the protopanaxadiols, $\mathrm{Rb} 2$ has been shown to significantly induce the expression of genes encoding antioxidant enzymes, such as SOD and catalase in vitro (25). Ginsenoside Rd has been shown to elevate intracellular glutathione levels by increasing the activation of $\gamma$-glutamyl cysteine ligase (GCL) in rat hepatocyte (H4IIE) cells through the induction of $\mathrm{NF}-\kappa \mathrm{B}$ DNA binding, but not altering Nrf2 DNA binding (26). As previously demonstrated, the induction of heme oxygenase-1 (HO-1) by ginsenoside 20(s)-protopanaxadiol inhibited the activation of inflammatory signaling molecules in murine Raw 264.7 macrophages stimulated with lipopolysaccharide (LPS) (27). The co-treatment of macrophages with HO-1 inhibitor abolished the inhibitory effects of this ginsenoside on the expression of inducible nitric oxide (NO) synthase (iNOS) and the activation of $\mathrm{NF}-\kappa \mathrm{B}(27)$. On the other hand, the treatment of HepG2 cells with Rb1, Rg1 or 20(s)-protopanaxatriol, or with a combination of 20(s)-protopanaxatriol with $\mathrm{Rb} 1$ or Rg1 has been shown to enhance the binding of Nrf2 to antioxidant response element (ARE), thereby increasing the total antioxidant activity (28). A previous study revealed that the treatment of Swiss albino mice with ginsenoside Rp1 for seven days by gavage significantly elevated the levels of skin microsomal cytochrome p-450 and cytochrome b5 and glutathione- $S$-transferase (GST), and reduced glutathione (GSH), glutathione peroxidase (GPx), glutathione reductase (GR), DT-diaphorase, SOD and catalase levels, resulting in the enhanced detoxification of carcinogens and the reduction of oxidative stress (12).

Anti-inflammatory effects. Since chronic inflammation contributes to the development and progression of tumors, the suppression of inflammatory signaling is a rational approach for cancer prevention and therapy. The anticancer 
activities of many phytochemicals have been linked to their anti-inflammatory effects. Several ginsenosides have been reported to interfere with inflammatory signaling, thereby inhibiting tumor promotion and progression $(8,9)$. The topical application of ginsenoside $\mathrm{Rg} 3$ has been shown to attenuate the TPA-induced activation of NF- $\mathrm{NB}$ and AP-1, and the expression of the pro-inflammatory enzyme, cyclooxygenase-2 (COX-2), accounting for its antitumor promoting effects in chemically-induced mouse skin carcinogenesis (11). As previously demonstrated, 20(S)- $\operatorname{Rg} 3$, a predominant stereospecific form of $\mathrm{Rg} 3$, inhibited the generation of ROS, but not that of NO, and decreased the production of cytokines, such as tumor necrosis factor- $\alpha$ (TNF- $\alpha$ ), interleukin (IL)- $1 \beta$, IL-6, and that of prostaglandin $\mathrm{E}_{2}\left(\mathrm{PGE}_{2}\right)$ in LPS-stimulated Raw 264.7 murine macrophages (29). Treatment with $\operatorname{Rg} 3$ also attenuated the LPS-induced expression of COX-2 in macrophages and reduced TNF- $\alpha$-induced matrix metalloproteinase (MMP)-9 activity in human keratinocyte (HaCaT) cells (29). Ginsenoside Rg5 has also been shown to attenuate LPS-induced lung inflammation in mice through the downregulation of $\mathrm{NF}-\kappa \mathrm{B}$ activity. $\mathrm{Rg} 5$ reduced the expression of pro-inflammatory mediators, such as COX-2, iNOS, IL-1 $\beta$ and TNF- $\alpha$ in LPS-stimulated alveolar macrophages by blocking the activities of IL-1 receptor-associated kinases (IRAKs) and $\mathrm{I} \kappa \mathrm{B}$ kinase $\beta$ (IKK $\beta$ ), and subsequently inhibiting the phosphorylation and nuclear accumulation of NF- $\kappa \mathrm{B}$ (30). Ginsenoside Rb1 and its intestinal metabolite, compound $\mathrm{K}$, also function through a similar mechanism in LPS-induced cytokine production in murine peritoneal macrophages. These ginseng saponins have been shown to inactivate IRAK1, IKK $\beta$, $\mathrm{NF}-\kappa \mathrm{B}$ and mitogen-activated protein (MAP) kinases (31). Moreover, the administration of Rb1 or compound $\mathrm{K}$ by gavage attenuated 2,4,6-trinitrobenzenesulfonic (TNBS) acid-induced colitis in mice by inhibiting colonic myeloperoxidase activity, decreasing the expression of COX-2, iNOS, TNF- $\alpha$, IL-1 $\beta$ and IL-6 through the inactivation of NF- $\kappa \mathrm{B}$ (31). Likewise, the oral administration of ginsenoside $\mathrm{Rd}$ to rats attenuated TNBS-induced colitis by inhibiting myeloperoxidase activity and preventing the production of cytokines, such as TNF- $\alpha$, IL- $1 \beta$ and IL- 6 through the blockade of p38 MAP kinase and c-Jun-N-terminal kinase (JNK) (32).

In previous studies, the treatment of Raw 264.7 macrophages with either Rb1 (33) or the ginseng metabolites, compound K (33) or 20(s)protopanaxatriol (34), diminished the LPS-induced expression of COX-2 and iNOS by blocking the activation of NF- $\mathrm{NB}$. Of note, the mutation of either NF- $\mathrm{B}$ - or CRE-binding sequences in the COX-2 promoter did not alter the inhibitory effects of Rb1 on TPA-induced COX-2 promoter activity; however, the effects were abrogated upon the mutation of NF-IL-6 binding sites. These findings suggest that NF-IL-6, but not NF- $\kappa \mathrm{B}$, is a target of $\mathrm{Rb} 1$ in suppressing COX-2 expression. In a recent study, Huang et al (35) demonstrated that Rg1 blocked the activation of transient receptor potential vanilloid-1 (TRPV1) and inhibited the transcriptional activity of NF- $\kappa \mathrm{B}$, thereby suppressing the expression of $\mathrm{COX}-2$, the production of $\mathrm{PGE}_{2}$ and the secretion of IL-8 in capsaicin-stimulated $\mathrm{HaCaT}$ keratinocytes, as well as in TRPV1-overexpressing human embryonic kidney (HEK)-293 cells (35). Likewise, co-treatment with ginsenoside $\mathrm{Rb}$ has been shown to diminish capsaicin-induced $\mathrm{NF}-\kappa \mathrm{B}$ transcriptional activity and reduce the release of IL- 8 and $\mathrm{PGE}_{2}$ in $\mathrm{HaCaT}$ keratinocytes by blocking the activation of TRPV1 (36).

Inhibition of proliferation and induction of apoptosis in cancer cells. The anti-proliferative and apoptotic effects of a wide variety of ginsenosides have been extensively investigated. The mechanisms by which selected ginsenosides inhibit proliferation and induce apoptosis in various cancer cells are discussed in this section.

Rg3. Several ginsenosides of the $\mathrm{Rg}$ series have been reported to inhibit proliferation and induce apoptosis in various cancer cells in culture. In a previous study, the treatment of human prostate cancer ( $\mathrm{LNCaP}$ ) cells with ginsenoside $\mathrm{Rg} 3$ reduced cell proliferation through $\mathrm{G} 1$ phase cell cycle arrest, which was associated with the decreased expression of the cyclin-dependent kinase (Cdk) inhibitors, p21 and p27 (37). The authors demonstrated that $\operatorname{Rg} 3$ also attenuated the expression of prostate-specific antigen (PSA), androgen receptor (AR), $5 \alpha$-reductase and proliferating cell nuclear antigen (PCNA). Moreover, $\mathrm{Rg} 3$ induced apoptosis in these cells by inhibiting Bcl-2 expression and inducing caspase-3 activity (37). Bae et al (13) recently demonstrated that $\mathrm{Rg} 3$ decreased the $\mathrm{AR}$ activity through the proteasomal degradation of AR and inhibited androgen-induced benign prostate hyperplasia in rats. $\mathrm{Rg} 3$ has also been shown to inhibit the expression of Bcl-2 and $\mathrm{Bcl}-\mathrm{xL}$, and induce the expression of Bax, resulting in reduced mitochondrial membrane potential, cytochrome $c$ release and the activation of caspase-3, thereby inducing apoptosis in human hepatocellular carcinoma cells (38-40) and human colon cancer (HT-29) cells (41). A recent study demonstrated that Rg3 sensitized several liver cancer (HepG2, SK-Hep1, Huh-7 and Hep3B) cells to TNF-related apoptosis-inducing ligand (TRAIL)induced apoptosis, but did not affect the survival of normal hepatocytes. The enhancement of TRAIL-sensitivity and the subsequent induction of cell death was mediated through the upregulation of death receptor-5 (DR5) through the activation of an endoplasmic reticulum (ER)-stress protein CCAAT/enhancer binding protein $(\mathrm{C} / \mathrm{EBP})$ homology protein $(\mathrm{CHOP})$, which is also known as growth arrest- and DNA damage-inducible gene 153 (GADD153) (42). The Rg3-induced activation of cyclic-AMPactivated protein kinase (AMPK) accounted for its apoptotic effects in HT-29 cells, as the co-treatment of cells with $\mathrm{Rg} 3$ in the presence of the AMPK inhibitor, compound C, or in cells transfected with AMPK-siRNA, abrogated Rg3-induced apoptosis (41). According to a recent study, $\mathrm{Rg} 3$ inhibited the growth and survival of human gastric cancer (AGS) cells by blocking the activity of the transient receptor potential melastatin-7 (TRPM7) channel. Rg3-mediated sub-G1 arrest, the cleavage of poly(ADP-ribose) polymerase (PARP) and the activation of caspases were abolished when AGS cells were co-treated with chemical inhibitors of TRPM7 (43). Chen et al (44) reported that Rg3 inhibited cell proliferation by blocking cell cycle progression and inducing apoptosis in B16 melanoma cells. Rg3 attenuated the proliferation of HCT116 cells in culture, at least in part, by decreasing the nuclear localization of $\beta$-catenin and downregulating $\beta$-catenin/T cell factor (TCF)-mediated transcriptional activity (14).

$R h 2$. Ginsenoside Rh2 has exhibited significantly more potent cell death activity than ginsenoside $\operatorname{Rg} 3$ in HCT-116 and SW-480 colorectal cancer cells through the generation 
of ROS, the activation of $\mathrm{p} 53$, the increased expression of Bax and the reduced expression of Bcl-2 (45). Likewise, in a previous study, the Rh2-induced apoptosis in MCF-7 and MDA-MB-231 cells was accompanied by the downregulation of the anti-apoptotic proteins, Bcl-2, Bcl-xL, Mcl-1, and the upregulation of the pro-apoptotic proteins, Bak, Bax and Bim, thereby enhancing the mitochondrial translocation of Bax and the activation of caspases (46). The authors also demonstrated that the administration of $\mathrm{Rh} 2$ by gavage significantly attenuated the growth of MDA-MB-231 cell tumor xenografts in nude mice (46). By contrast, Rh2 was also found to induce apoptosis in rat glioma cells independent of Bcl-2, as $\mathrm{Rh} 2$ did not induce apoptosis in Bcl-2-overexpressing glioma cells $(47,48)$. Likewise, a Bcl-2-insensitive activation of caspase-3 was associated with the Rh2-mediated apoptosis of human hepatoma SK-HEP1 cells (49). Whereas $\mathrm{Rh} 2$ significantly inhibited the proliferation of intestinal cancer (Int-407 and Caco-2) cells through sub-G1 arrest, the structurally related ginsenoside Rh1 failed to inhibit cell proliferation (50). Oh et al (51) demonstrated that Rh2 induced G1 phase arrest and reduced the proliferation of MCF-7 cells, partly by decreasing the phosphorylation of retinoblastoma protein and increasing the binding of retinoblastoma protein with E2F1 by downregulating the activities of Cdk-2 and cyclin E, and the induction of Cdk inhibitor p21. Likewise, the Rh2-mediated G1 arrest in A549 cells has been shown to be associated with the reduced expression and the activity of cyclin D1, cyclin E and Cdk-6, and increased the expression of $\mathrm{Rb}$ (52). The authors demonstrated that $\mathrm{Rh} 2$ induced apoptosis by increasing the expression of DR4 and the subsequent activation of caspases-2, -3 and -8 (52). The treatment of human neuroblastoma (SK-N-BE) cells with $\mathrm{Rh} 2$ has been shown to increase cell death through the induction of caspase-1 and -3 activity, the expression of p53 and Bax and the cleavage of PARP (10). In a previous study, the pro-apoptotic effects of Rh2 in SK-HEP1 cells were mediated by the caspase-3-dependent activation of protein kinase $\mathrm{C}-\delta$ (PKC- $\delta$ ). The treatment of cells with caspase-3 inhibitor attenuated $\mathrm{Rh} 2$-induced proteolytic cleavage and the activation of PKC- $\delta$. The blockade of caspase- 3 activity or the pharmacological inhibition of PKC $\delta$ abrogated $\mathrm{Rh} 2$-induced apoptosis in these cells (53). Moreover, the generation of ROS, the activation of JNK1, the depolarization of mitochondrial membrane potential and the subsequent activation of caspase- 3 have been shown to be associated with $\mathrm{Rh} 2$-induced apoptosis in HeLa cells, which were abrogated by the overexpression of catalase or treatment with $\mathrm{N}$-acetyl cysteine (NAC) (54).

Another mechanism of Rh2-induced apoptosis in cancer cells involves the disruption of membrane lipid rafts, thereby resulting in the inactivation of Akt signaling and the subsequent inhibition of Bad phosphorylation and the increased expression of the pro-apoptotic proteins, Bim and Bax, in MDA-MB-231 cells (55). The treatment of HeLa cells with Rh2 has been shown to induce apoptosis through the disruption of physical and chemical properties of membrane lipid rafts through the internalization of caveolin-1 and GM1, followed by the ligandindependent oligomerization of FAS, which was abrogated by cholesterol overloading or transfection with FAS siRNA (56). Recent studies have demonstrated that Rh2 inhibits cancer cell proliferation and induces apoptosis by modulating the function of certain micro-RNAs (miRs) (57,58). For example, the miR array analysis of Rh2-treated human glioma (U251) cells revealed the upregulation of $14 \mathrm{miRs}$ and the downregulation of 12 miRs. Transfection with miR-128 inhibitor prevented the overexpression of miR-128 in Rh2-treated U251 cells and blunted Rh2-induced apoptosis by blocking the activation of caspase- 3 and the transcriptional activation of the miR-128 target gene, E2F3a (58).

$R p 1 . \mathrm{Rp} 1$ is semi-synthesized from crude ginsenosides (59). The incubation of human breast cancer cells with ginsenoside $\mathrm{Rp} 1$ has been shown to attenuate anchorage-dependent and -independent colony formation, which was associated with the reduced stability of insulin-like growth factor receptor (60). In a previous study, Rp1 induced G1 phase arrest in HeLa cells by inhibiting the expression of cyclin D1, E and $\mathrm{A}$, and increasing the expression of $\mathrm{p} 21$ without affecting the levels of p53 or serine-15 phosphorylated p53. In addition, prolonged incubation with Rp1 activated caspase- $3,-8$ and -9 by stimulating the mitochondrial release of cytochrome $c$ through the activation of Bax and Bid, and the subsequent loss of mitochondrial membrane potential. This led to the Rp1-induced cleavage of PARP and the induction of apoptosis in HeLa cells (61).

Rkl. Ginsenoside Rk1 is a major bioactive component of heat-processed ginseng. The concentration- and time-dependent cytotoxic effects of Rk1 in human melanoma (SK-MEL2) cells have been shown to be associated with the upregulation of Fas, FasL and Bax protein and the downregulation of procaspase- 8 and -3 , mutant $\mathrm{p} 53$ and Bcl-2 protein expression (62). Likewise, the activation of caspase- 3 and -8 by Rk1 induced apoptosis in HepG2 cells (63).

Others. Kim et al (64) reported that a diol-type ginseng saponin Rs 3 induced cell cycle arrest at the G1/S boundary in SK-HEP-1 cells by increasing the expression $\mathrm{p} 53$ and p21 without affecting the expression of cyclin E and cyclin A, p27 and PCNA. However, Rs 3 was found to inhibit the activities of cyclin E- and cyclin A-associated kinases in these cells (64). The G1 phase cell cycle arrest was also evident in human lung cancer (A549, H358 and H838) cells treated with 25-methoxyprotopanaxadiol, which did not affect the viability of normal lung epithelial (BAES-2B) cells (18). In a previous study, 25-hydroxy-protopanaxadiol, but not 25-hydroxy-protopanaxatriol induced cell cycle arrest, as well as apoptosis in PC3 and $\mathrm{LNCaP}$ cells by increasing the expression of p21, p27 and Bax, and activating caspases and inducing the cleavage of PARP. Moreover, 25-hydroxy-protopanaxadiol has been shown to reduce the expression of mouse double minute 2 (MDM2), E2F1, Bcl-2, Cdk-2/4/6 and cyclin D1 as the underlying molecular mechanisms of the anti-proliferative effects of this ginsenoside (65). Similarly, $25-\mathrm{OCH}_{3}$-protopanaxadiol has been shown to decrease the proliferation of human breast cancer cells by inducing G1 phase cell cycle arrest and diminishing MDM2 expression (20).

Compound $\mathrm{K}$, the intestinal metabolite of ginsenoside $\mathrm{Rb} 1$, has been shown to decrease cell viability by inducing $\mathrm{G} 2$ phase arrest and apoptosis in human gastric carcinoma (BGC823 and SGC7901) cells through the upregulation of $\mathrm{p} 21$ and the downregulation of cdc2 and cyclin B1 (17). Incubation with compound $\mathrm{K}$ induced sub-G1 arrest in human multiple myeloma 
(U266) cells by blocking the phosphorylation of signal transducer and activator of transcription (STAT) 3 and upstream janus-activated kinase (JAK)1, but not JAK2, and diminishing the expression of STAT3 target genes, such as Bcl-2, Bcl-xL and cyclin D1 (66). The authors demonstrated that compound K induced the expression of protein phosphatase (PTP) and that treatment with pervanadate, a PTP inhibitor, abrogated the inhibitory effects of compound K on STAT3 phosphorylation and its target gene expression (66).

Recent molecular docking studies with several ginsenosides have revealed that $\mathrm{Rf}, \mathrm{Rg} 1, \mathrm{Rg} 3$ and $\mathrm{Rh} 2$ have more binding affinity with Bcl-2, Bcl-xL and Mcl-1 than other ginsenosides, which have relatively lower binding affinity to anti-apoptotic proteins. Therefore, ginsenosides represent a novel class of potent inhibitors of anti-apoptotic proteins and may be used for cancer chemotherapy (67). The antiproliferative and apoptotic effects of ginsenosides are linked to their structural features. It has been reported that ginsenoside 20(S)-Rh2, but not its stereoisomer ginsenoside 20(R)-Rh2 inhibited the proliferation of androgen-dependent and -independent prostate cancer cells in vitro, suggesting that the stereochemistry of the hydroxyl group at C-20 may play an important role in the antitumor activity of ginsenoside $\mathrm{Rh} 2$ (68). In vitro structure-related antitumor activity analysis revealed that the induction of apoptosis in various cancer cells was in the order of protopanaxadiol $>20$ (S)-Rh2 >20(R)-Rh2 $\approx 20(\mathrm{R})-\mathrm{Rg} 3 \approx 20$ (S)-Rg3. These results suggest that ginsenosides with less polar chemical structures possesses higher cytotoxic activity in cancer cells. The cytotoxic potential of protopanaxadiol was further increased by products obtained through hydrogenation and the dehydration of protopanaxadiol (69).

Anti-angiogenic activity. One of the hallmarks of cancer is aberrant tumor angiogenesis. As peviously demonstrated, the treatment of human esophageal carcinoma cells with ginsenoside Rg3 in presence of hypoxia resulted in reduced mRNA expression and the production of vascular endothelial growth factor (VEGF), which was associated with the decreased expression of hypoxia inducible factor $1 \alpha(\mathrm{HIF} 1 \alpha)$ and COX-2 and the diminished NF- $\mathrm{KB}$ activity. Moreover, Rg3 attenuated the hypoxia-induced phosphorylation of extracellular signal-regulated kinase (ERK1/2), JNK and STAT3 in these cells (70). Treatment with $\operatorname{Rg} 3$ dose dependently suppressed the VEGF-induced capillary tube formation of human umbilical vein endothelial cells (HUVECs) on Matrigel and ex vivo microvascular sprouting in rat aortic ring assay through the inhibition of MMP-2 and MMP-9 activity (71). When administered in combination with gemcitabine, $\operatorname{Rg} 3$ has been shown to significantly reduce the growth of Lewis lung carcinoma cells transplanted in C57BL/6 mice with a marked decrease in microvessel density and the reduced expression of VEGF, thereby preventing tumor angiogenesis (15). Likewise, the combination of $\mathrm{Rg} 3$ with capecitabine (72) or cyclophosphamide (73) augmented the angiosuppressive activity of these chemotherapeutic agents in human breast and ovarian cancer, respectively. According to the latter study, Rg3 alone or in combination with cyclophosphamide attenuated the growth of human ovarian cancer (SKOV-3) cell xenografts in nude mice and induced a significant decrease in the expression of PCNA and VEGF (73). Zhang et al (74) also demonstrated that in the presence of Rg3, a low dose of cyclophosphamide was effective in suppressing the growth of Lewis lung carcinoma cells by inhibiting angiogenesis.

Endothelial progenitor cells (EPCs) appear to play a key role in the growth of early tumors. In a recent study, Kim et al (75) demonstrated that the treatment of ex vivo cultured endothelial cells, a type of EPCs, with Rg3 inhibited proliferation, migration and tubular formation by blocking the VEGF-dependent activation of ERK and p38 MAP kinases and inhibiting the mobilization of EPCs from the bone marrow microenvironment to the peripheral circulation. The intratumoral or oral administration of another ginsenoside $\mathrm{Rb} 2$ has been shown to inhibit tumor angiogenesis in a model of B16-BL6 melanoma cell xenografts in nude mice. However, the intravenous administration of $\mathrm{Rb} 2$ failed to inhibit the growth of xenograft tumors. Moreover, $\mathrm{Rb} 2$ did not affect the growth of rat lung endothelial cells, B16-BL6 melanoma cells or various types of murine normal cells in vitro (76). Compound $\mathrm{K}$ significantly inhibited the migration and tube formation in basic fibroblast growth factor (bFGF)-treated HUVECs and reduced the secretion of VEGF and increased the production of pigment epithelium-derived factor. Moreover, compound $\mathrm{K}$ attenuated the phosphorylation of p38 MAP kinase and Akt in bFGFstimulated HUVECs, and inhibited neovascularization in the Matrigel plugs excised from mice in vivo (77).

Attenuation of invasion and metastasis. Incubation with $\operatorname{Rg} 3$ has been shown to reduce the migration of highly metastatic prostate cancer (PC3M) cells by downregulating the expression of aquaporin-1 (AQP1), a water channel protein that has been implicated in cell migration, through the blockade of p38 MAP kinase phosphorylation. The inhibitory effects of $\mathrm{Rg} 3$ on the migration of these cells were annulled either by the overexpression of AQP1 or by the pharmacological inhibition of p38 MAP kinase (78). Ginsenosides Rg3 and Rb2 have been shown to significantly inhibit the adhesion of B16-BL6 melanoma cells to fibronectin and laminin, and attenuate the invasion of these cells into the reconstituted basement membrane in a dose-dependent manner. Moreover, the lung metastasis of B16-BL6 or colon 26-M3.1 cells in nude mice was significantly inhibited by the intravenous or oral administration of $\mathrm{Rg} 3$ or $\mathrm{Rb} 2$ (79). Likewise, treatment with $\mathrm{Rg} 3$ has been shown to markedly reduce the expression of MMP-9 and decrease the invasive and metastatic ability (metastasis to lungs) of SKOV-3 cells in mice (80). Moreover, a previous study demonstrated that the intraperitoneal administration of Rg3 prevented the metastasis (to the lungs) of B16 melanoma cells (44).

In another study, treatment with Rg3 elicited a decreased expression of chemokine receptor CXCR4 in MDA-MB-231 cells and reduced chemokine CXCL12-induced migration of these cells (81). Although $\operatorname{Rg} 3$ failed to affect bombesin-induced intestinal carcinogenesis, the ginsenoside significantly decreased the peritoneal metastasis of intestinal adenocarcinomas (82). $\operatorname{Rg} 3$ has also been shown to inhibit the invasion of rat ascites hepatoma cells (MM1), B16FE7 melanoma cells, human small cell lung carcinoma and human pancreatic adenocarcinoma cells in a cell monolayer invasion assay (83). Moreover, Rg3 attenuated experimental pulmonary metastasis by highly metastatic mouse melanoma (B16FE7) 
cells. The authors demonstrated that $\operatorname{Rg} 2$ and $\mathrm{Rb} 2$ mildly inhibited invasion, but Rh1, Rh2, Rb1, Rc or Re had no effect the invasive ability of these cells (83). By contrast, ginsenoside Rh1 (84) and Rd (85) suppressed the invasion and metastasis of human hepatocellular carcinoma HepG2 cells. According to the former study, Rh1 inhibited the mRNA expression and the promoter activity of MMP-1 by blocking the activation of MAP kinases, such as ERK, p38 MAP kinase and JNK. In addition, Rh1 diminished the phorbol ester-induced expression of c-Jun and c-Fos, but failed to affect the DNA binding of AP-1 in HepG2 cells (84). Treatment with ginsenoside Rd has been shown to prevent the invasion and migration of HepG2 cells by downregulating the expression of MMP-1, MMP-2 and MMP-7, by blocking the phosphorylation of ERK and p38 MAP kinase and by inhibiting the activation of AP-1 (85). Likewise, ginsenoside Rh2 has been shown to inhibit phorbol ester-induced MMP-9 mRNA expression and diminish the invasion of astroglioma cells by blocking the activation of $\mathrm{NF}-\kappa \mathrm{B}$ and AP-1 through the inhibition of p38 MAP kinase, ERK and JNK phosphorylation (86). Rp1 markedly inhibited the metastatic lung transfer of B16-F10 melanoma cells, presumably by inhibiting the expression of $\beta 1$-integrin, a cell surface receptor that plays a key role in cell-matrix interaction (59).

Ginseng saponins are metabolized by intestinal bacteria and produce a variety of metabolites, which also exhibit anti-invasive and antimetastatic properties. For instance, compound $\mathrm{K}$ markedly attenuated the colony formation, adhesion and invasion of hepatocellular carcinoma (HCC) cells in vitro and markedly inhibited spontaneous HCC cell metastatic growth in vivo. This study also demonstrated that treatment with compound $\mathrm{K}$ diminished the nuclear accumulation of p65 and significantly reduced the expression of MMP-2 and MMP-9 (87). The intestinal bacterial metabolite of Rb1 is 20-O- $\beta$-D-glucopyranosyl-20(S)-protopanaxadiol (M1). The inhibition of spontaneous metastasis produced by the subcutaneous administration of Lewis lung carcinoma cells in syngenic C57BL/6 mice by Rb1 has been reported to be the effect of its metabolite M1 (88). The anti-metastatic effect of this ginsenoside metabolite was comparable to that of the chemotherapeutic drug, 5-fluorouracil. Treatment with M1 inhibited the TNF- $\alpha$-induced activation of $N F-\kappa B$ and reduced the expression of MMP-9, thereby suppressing the invasion and migration of colon adenocarcinoma cells. Moreover, the TNF- $\alpha$-induced increase in lung and liver metastasis of colon carcinoma was also abrogated by treatment with M1 (89).

Chemosensitizing and radiosensitizing effects. Resistance to chemotherapy and radiotherapy is an emerging challenge in reducing the global burden of cancer. Attention has recently been paid to a wide variety of natural compounds which enhance the sensitivity of various resistant cancer cells to conventional chemotherapy and radiotherapy. Several ginsenosides and their intestinal bacterial metabolites have been reported to increase the chemosensitivity and radiosensitivity of cancer cells. Kim et al (90) investigated the effects of a combination of ginsenoside $\mathrm{Rg} 3$ with chemotherapeutic agents, such as docetaxel, paclitaxel, cisplatin and doxorubicin on the growth of colon cancer (SW480 and HCT-116) cells.
Compared with treatment with individual chemotherapeutic agents or $\operatorname{Rg} 3$, the combination of each of the anticancer drugs with Rg3 elicited more pronounced anti-proliferative effects on these cells. Moreover, treatment with a combination of $\mathrm{Rg} 3$ and docetaxel induced apoptosis in these colon cancer cells by inhibiting the activity of $\mathrm{NF}-\kappa \mathrm{B}$, inducing the expression of pro-apoptotic proteins (Bax, caspase-3 and -9) and decreasing the expression of anti-apoptotic proteins [Bcl-2, X-linked inhibitor of apoptosis (XIAP), inhibitor of apoptosis (IAP)1, COX-2 and cyclin D1], compared with the effects observed by treatment with docetaxel alone (90). The authors also demonstrated that $\mathrm{Rg} 3$ increased the susceptibility of human prostate cancer (LNCaP, PC3 and DU145) cells to docetaxel, cisplatin and doxorubicin. Compared to treatment with $\mathrm{Rg} 3$ or docetaxel alone, the combination treatment of $\operatorname{Rg} 3$ with docetaxel was more effective in the inhibition of prostate cancer cell growth and the induction of apoptosis, as well as G0/G1 cell cycle arrest accompanied by the significant inhibition of NF- $\kappa$ B activity (91). Likewise, in another study, the effects of combinations of Rh2 or its aglycon with docetaxel were predominantly additive or synergistic in PC3, DU145 and C4-2 prostate cancer cells. Combinations of Rh2 or its aglycon with docetaxel induced the regression of established PC3 tumors from their initial size by 15 and 27\%, respectively, and reduced the expression of cell proliferation marker Ki-67 as compared with animals treated with docetaxel alone (92).

In a previous study, a combination of $\operatorname{Rg} 3$ and gemcitabine enhanced the growth-suppressive effect of gemcitabine in C57BL/6 mice bearing Lewis lung carcinoma cells and prolonged the survival of these tumor-bearing mice (15). $\operatorname{Rg} 3$ has been reported to enhance the penetration of paclitaxel into Caco-2 monolayer cells by downregulating the expression of p-glycoprotein (P-gp), also known as multidrug resistance protein-1 (MDR1), increasing the oral bioavailability of paclitaxel in rats. The enhancement of the oral bioavailability of paclitaxel by $\operatorname{Rg} 3$ was further established by the finding that the oral administration of a combination of paclitaxel and $\operatorname{Rg} 3$ attenuated the growth of MCF-7 breast cancer cell xenografts in nude mice more effectively than treatment with paclitaxel alone (93).

Resistance to chemotherapy is associated with the overexpression of the MDRl gene. Ginsenosides $\mathrm{Rd}, \mathrm{Re}, \mathrm{Rb} 1$ and Rg1 have been shown to reduce the expression of MDR1 in chemoresistant breast cancer (MCF7/ADR) cells. Further investigation with $\mathrm{Rd}$ ginsenoside revealed that $\mathrm{Rd}$ failed to alter the transcription of MDR1 but induced the ubiquitindependent proteasomal degradation of MDR1 and reversed the doxorubicin resistance of these cells (94). In another study, $\mathrm{Rg} 3$ potentiated the cytotoxic effects of cisplatin in CT-26 colon cancer cells by blocking the cisplatin-induced activation of Nrf2 and the expression of antioxidant enzymes HO-1 and NADPH:quinone oxidoreductase 1 (NQO1). In addition, the combination with $\mathrm{Rg} 3$ reduced the cytotoxic effects of cisplatin in normal LLC-RK1 kidney and NCTC1469 liver cells, suggesting that $\mathrm{Rg} 3$ is effective in relieving the renal and hepatic toxicity of cisplatin (95).

A synergistic inhibitory effect of ginsenoside $\mathrm{Rh} 2$ and cisplatin on the growth of a cell line (HRA) derived from ascites of a patient with serous cystadenocarcinoma of the ovary has been reported (96). According to the authors, Rh2 
alone did not exhibit any significant growth inhibition of HRA cell xenografts in nude mice, but a combination of Rh2 with cisplatin induced a more pronounced inhibition of xenograft tumor growth, compared with treatment with cisplatin alone (96). Similarly, the treatment of LNCaP cell xenograft tumors with Rh2 plus paclitaxel has been shown to induce a significant decrease in tumor growth and serum PSA levels, suggesting a synergistic effect of Rh2 and paclitaxel (97). In another study, $\mathrm{Rh} 2$ induced apoptosis in multidrug-resistant human breast cancer cells by hypersensitizing these cells to paclitaxel. The apoptosis induced by $\mathrm{Rh} 2$ in combination with paclitaxel was mediated through the activation of glucocorticoid receptor, but not the expression of p53 or caspase-3 (98). Chae et al (99) reported that the treatment of NCI-H460 human lung cancer cells with compound $\mathrm{K}$ and simultaneous exposure to gamma-radiation resulted in the increased apoptosis of these cells through the generation of ROS and the activation of caspase-3. Moreover, the combination of compound $\mathrm{K}$ and gamma-ray led to the enhanced regression of NCI-H460 tumor xenografts in nude mice (99).

\section{Future perspectives}

The molecular target-based prevention of cancer has been widely accepted as a rational and practical strategy to reduce the global burden of cancer. A number of dietary phytochemicals have been reported to prevent cancer by targeting diverse intracellular signaling molecules implicated in the carcinogenic process. Extensively investigated ginseng and its vast array of saponins are attractive candidates for the development of chemopreventive and/or chemotherapeutic agents. As discussed in this review, studies on individual ginsenosides have revealed that many of them function through similar mechanisms by inhibiting growth or inducing apoptosis in cancer cells. Thus, it would be worthy to formulate a combination of ginsenosides, which would be multitargeting and may be more portent in preventing tumor growth. Such a formulation is KG-135, which is a mixture of ginsenosides $\mathrm{Rk} 1$, Rg3 and Rg5. The incubation of human mammary epithelial cells with KG-135 has been shown to inhibit the TPA-induced expression of COX-2 by blocking the activation of NF- $\kappa \mathrm{B}$ and AP-1 (100). In another study, KG-135 diminished the proliferative ability of human prostate cancer (DU-145 and PC3) cells and reduced the growth of PC3 cell tumor xenografts in nude mice by inducing cell cycle arrest through the downregulation of cyclin D1 and Cdk expression (101). Moreover, KG-135 has been shown to enhance etoposide-induced apoptosis in HeLa cells by activating p53 and inducing the expression of Bax and p21 (102). These findings indicate that there is ample scope to develop novel ginsenoside formulations by mixing different types of ginsenosides. However, caution should be exercised before such attempts, as there have been reports that certain ginsenosides can promote tumor progression. For example, ginsenoside $\mathrm{Rh} 2$ has been shown to enhance the metastatic potential of BALB/c 3T3 cells in mice (103). Whereas the majority of ginsenosides inhibit inflammation, ginsenoside $\mathrm{Rd}$ has been shown to induce the expression of COX-2 and increase the production of $\mathrm{PGE}_{2}$ in Raw 264.7 macrophages by enhancing the DNA binding of C/EBP and cyclic-AMP response element binding protein (CREB) (104). Therefore, the combination of ginsenosides in the development of novel formulas for chemoprevention and/or chemotherapy must be carried out judiciously so that the overall therapeutic benefit may be best achieved.

A few studies have demonstrated the prolongation of survival and improvement of quality of life in cancer patients receiving ginseng or its component, ginsenoside $\operatorname{Rg} 3(105,106)$. Kim et al (105) reported that a 12-week therapy with ginseng improved the mental and physical health of patients diagnosed with gynecological cancer and hepatobiliary cancer. The administration of ginsenoside Rg3 together with chemotherapy has also been shown to increase the post-surgical life span of patients suffering from non-small cell lung cancer (106). These limited clinical experiences and extensive preclinical study outcomes indicate the potential of ginsenosides or their formulations in cancer prevention and therapy. Further clinical trials with ginsenosides or their combinations, and extensive pharmacokinetic studies are required to perform dosage adjustment and to achieve bioavailable doses of ginsenosides. It should also be taken into consideration that ginsenosides, when administered by gavage, can undergo intestinal metabolism, which often produces active metabolites. Thus, more rigorous studies in terms of bioavailability, metabolism and dose-response relationships would make this age-old oriental medicine exploitable for cancer chemoprevention and/or chemotherapy.

\section{Acknowledgements}

This study was supported by the Settlement Research Grant-2012-0195 of Keimyung University allocated to Joydeb Kumar Kundu.

\section{References}

1. Choi KT: Botanical characteristics, pharmacological effects and medicinal components of Korean Panax ginseng C A Meyer. Acta Pharmacol Sin 29: 1109-1118, 2008.

2. Shibata S: Chemistry and cancer preventing activities of ginseng saponins and some related triterpenoid compounds. J Korean Med Sci 16 (Suppl): S28-S37, 2001.

3. Kitagawa I, Taniyama T, Shibuya H, Noda T and Yoshikawa M: Chemical studies on crude drug processing. V. On the constituents of ginseng radix rubra (2): Comparison of the constituents of white ginseng and red ginseng prepared from the same Panax ginseng root. Yakugaku Zasshi 107: 495-505, 1987 (In Japanese).

4. Kitagawa I, Yoshikawa M, Yoshihara M, Hayashi $\mathrm{T}$ and Taniyama T: Chemical studies of crude drugs (1). Constituents of Ginseng radix rubra. Yakugaku Zasshi 103: 612-622, 1983 (In Japanese).

5. Shin HR, Kim JY, Yun TK, Morgan G and Vainio H: The cancerpreventive potential of Panax ginseng: a review of human and experimental evidence. Cancer Causes Control 11: 565-576, 2000.

6. Yun TK, Lee YS, Lee YH, Kim SI and Yun HY: Anticarcinogenic effect of Panax ginseng C.A. Meyer and identification of active compounds. J Korean Med Sci 16 (Suppl): S6-S18, 2001.

7. Nag SA, Qin JJ, Wang W, Wang MH, Wang H and Zhang R: Ginsenosides as anticancer agents: In vitro and in vivo activities, structure-activity relationships, and molecular mechanisms of action. Front Pharmacol 3: 25, 2012.

8. Qi LW, Wang CZ and Yuan CS: Ginsenosides from American ginseng: chemical and pharmacological diversity. Phytochemistry 72: 689-699, 2011.

9. Hofseth LJ and Wargovich MJ: Inflammation, cancer, and targets of ginseng. J Nutr 137 (Suppl 1): 183S-185S, 2007. 
10. Kim YS and Jin SH: Ginsenoside Rh2 induces apoptosis via activation of caspase-1 and -3 and up-regulation of Bax in human neuroblastoma. Arch Pharm Res 27: 834-839, 2004.

11. Keum YS, Han SS, Chun KS, et al: Inhibitory effects of the ginsenoside $\mathrm{Rg} 3$ on phorbol ester-induced cyclooxygenase-2 expression, NF-kappaB activation and tumor promotion. Mutat Res 523-524: 75-85, 2003.

12. Kumar A, Kumar M, Panwar M, et al: Evaluation of chemopreventive action of Ginsenoside Rp1. Biofactors 26: 29-43, 2006.

13. Bae JS, Park HS, Park JW, Li SH and Chun YS: Red ginseng and $20(\mathrm{~S})-\mathrm{Rg} 3$ control testosterone-induced prostate hyperplasia by deregulating androgen receptor signaling. J Nat Med 66 $476-485,2012$

14. He BC, Gao JL, Luo X, et al: Ginsenoside Rg3 inhibits colorectal tumor growth through the down-regulation of Wnt/ $\beta$-catenin signaling. Int J Oncol 38: 437-445, 2011.

15. Liu TG, Huang Y, Cui DD, et al: Inhibitory effect of ginsenoside $\mathrm{Rg} 3$ combined with gemcitabine on angiogenesis and growth of lung cancer in mice. BMC Cancer 9: 250, 2009.

16. Musende AG, Eberding A, Wood C, et al: Pre-clinical evaluation of Rh2 in PC-3 human xenograft model for prostate cancer in vivo: formulation, pharmacokinetics, biodistribution and efficacy. Cancer Chemother Pharmacol 64: 1085-1095, 2009.

17. Hu C, Song G, Zhang B, et al: Intestinal metabolite compound $\mathrm{K}$ of panaxoside inhibits the growth of gastric carcinoma by augmenting apoptosis via Bid-mediated mitochondrial pathway. J Cell Mol Med 16: 96-106, 2012.

18. Wang W, Rayburn ER, Hang J, Zhao Y, Wang H and Zhang R: Anti-lung cancer effects of novel ginsenoside 25-OCH(3)-PPD. Lung Cancer 65: 306-311, 2009.

19. Wang W, Rayburn ER, Zhao Y, Wang H and Zhang R: Novel ginsenosides 25-OH-PPD and 25-OCH3-PPD as experimental therapy for pancreatic cancer: anticancer activity and mechanisms of action. Cancer Lett 278: 241-248, 2009.

20. Wang W, Zhang X, Qin JJ, et al: Natural product ginsenoside $25-\mathrm{OCH}_{3}-\mathrm{PPD}$ inhibits breast cancer growth and metastasis through down-regulating MDM2. PLoS One 7: e41586, 2012.

21. Wang W, Rayburn ER, Hao M, et al: Experimental therapy of prostate cancer with novel natural product anti-cancer ginsenosides. Prostate 68: 809-819, 2008.

22. Lü JM, Weakley SM, Yang Z, Hu M, Yao Q and Chen C: Ginsenoside rb1 directly scavenges hydroxyl radical and hypochlorous acid. Curr Pharm Des 18: 6339-6347, 2012.

23. Park HM, Kim SJ, Mun AR, et al: Korean red ginseng and its primary ginsenosides inhibit ethanol-induced oxidative injury by suppression of the MAPK pathway in TIB-73 cells. J Ethnopharmacol 141: 1071-1076, 2012.

24. Kim YH, Park KH and Rho HM: Transcriptional activation of the $\mathrm{Cu}, \mathrm{Zn}$-superoxide dismutase gene through the AP2 site by ginsenoside $\mathrm{Rb} 2$ extracted from a medicinal plant, Panax ginseng. J Biol Chem 271: 24539-24543, 1996.

25. Chang MS, Lee SG and Rho HM: Transcriptional activation of $\mathrm{Cu} / \mathrm{Zn}$ superoxide dismutase and catalase genes by panaxadiol ginsenosides extracted from Panax ginseng. Phytother Res 13: 641-644, 1999.

26. Kim ND, Pokharel YR and Kang KW: Ginsenoside Rd enhances glutathione levels in H4IIE cells via NF-kappaB-dependent gamma-glutamylcysteine ligase induction. Pharmazie 62: 933-936, 2007.

27. Lee SH, Seo GS, Ko G, Kim JB and Sohn DH: Anti-inflammatory activity of 20(S)-protopanaxadiol: enhanced heme oxygenase 1 expression in RAW 264.7 cells. Planta Med 71: 1167-1170, 2005.

28. Saw CL, Yang AY, Cheng DC, et al: Pharmacodynamics of ginsenosides: antioxidant activities, activation of $\mathrm{Nrf} 2$, and potential synergistic effects of combinations. Chem Res Toxicol 25: $1574-1580,2012$

29. Shin YM, Jung HJ, Choi WY and Lim CJ: Antioxidative, antiinflammatory, and matrix metalloproteinase inhibitory activities of 20(S)-ginsenoside $\mathrm{Rg} 3$ in cultured mammalian cell lines. $\mathrm{Mol}$ Biol Rep 40: 269-279, 2013.

30. Kim TW, Joh EH, Kim B and Kim DH: Ginsenoside Rg5 ameliorates lung inflammation in mice by inhibiting the binding of LPS to toll-like receptor-4 on macrophages. Int Immunopharmacol 12: 110-116, 2012

31. Joh EH, Lee IA, Jung IH and Kim DH: Ginsenoside Rb1 and its metabolite compound K inhibit IRAK-1 activation - the key step of inflammation. Biochem Pharmacol 82: 278-286, 2011.
32. Yang XL, Guo TK, Wang YH, et al: Ginsenoside Rd attenuates the inflammatory response via modulating p38 and JNK signaling pathways in rats with TNBS-induced relapsing colitis. Int Immunopharmacol 12: 408-414, 2012.

33. Park EK, Shin YW, Lee HU, et al: Inhibitory effect of ginsenoside $\mathrm{Rb} 1$ and compound $\mathrm{K}$ on $\mathrm{NO}$ and prostaglandin $\mathrm{E} 2$ biosyntheses of RAW264.7 cells induced by lipopolysaccharide. Biol Pharm Bull 28: 652-656, 2005.

34. Oh GS, Pae HO, Choi BM, et al: 20(S)-Protopanaxatriol, one of ginsenoside metabolites, inhibits inducible nitric oxide synthase and cyclooxygenase-2 expressions through inactivation of nuclear factor-kappaB in RAW 264.7 macrophages stimulated with lipopolysaccharide. Cancer Lett 205: 23-29, 2004.

35. Huang J, Ding L, Shi D, et al: Transient receptor potential vanilloid-1 participates in the inhibitory effect of ginsenoside Rg1 on capsaicin-induced interleukin- 8 and prostaglandin E2 production in HaCaT cells. J Pharm Pharmacol 64: 252-258, 2012.

36. Huang J, Qiu L, Ding L, et al: Ginsenoside Rb1 and paeoniflorin inhibit transient receptor potential vanilloid-1-activated IL-8 and $\mathrm{PGE}_{2}$ production in a human keratinocyte cell line HaCaT. Int Immunopharmacol 10: 1279-1283, 2010.

37. Liu WK, Xu SX and Che CT: Anti-proliferative effect of ginseng saponins on human prostate cancer cell line. Life Sci 67: $1297-1306,2000$

38. Jiang JW, Chen XM, Chen XH and Zheng SS: Ginsenoside Rg3 inhibit hepatocellular carcinoma growth via intrinsic apoptotic pathway. World J Gastroenterol 17: 3605-3613, 2011.

39. Park HM, Kim SJ, Kim JS and Kang HS: Reactive oxygen species mediated ginsenoside $\mathrm{Rg} 3$ - and $\mathrm{Rh} 2$-induced apoptosis in hepatoma cells through mitochondrial signaling pathways. Food Chem Toxicol 50: 2736-2741, 2012.

40. Zhang C, Liu L, Yu Y, Chen B, Tang C and Li X: Antitumor effects of ginsenoside $\mathrm{Rg} 3$ on human hepatocellular carcinoma cells. Mol Med Rep 5: 1295-1298, 2012.

41. Yuan HD, Quan HY, Zhang Y, Kim SH and Chung SH: 20(S)-Ginsenoside Rg3-induced apoptosis in HT-29 colon cancer cells is associated with AMPK signaling pathway. Mol Med Rep 3: 825-831, 2010.

42. Lee JY, Jung KH, Morgan MJ, et al: Sensitization of TRAILinduced cell death by $20 \mathrm{~S}$-Ginsenoside Rg3 via CHOP-mediated DR5 upregulation in human hepatocellular carcinoma cells. Mol Cancer Ther 12: 274-285, 2012.

43. Kim BJ, Nah SY, Jeon JH, So I and Kim SJ: Transient receptor potential melastatin 7 channels are involved in ginsenoside Rg3-induced apoptosis in gastric cancer cells. Basic Clin Pharmacol Toxicol 109: 233-239, 2011.

44. Chen J, Peng H, Ou-Yang X and He X: Research on the antitumor effect of ginsenoside Rg3 in B16 melanoma cells. Melanoma Res 18: 322-329, 2008

45. Li B, Zhao J, Wang CZ, et al: Ginsenoside Rh2 induces apoptosis and paraptosis-like cell death in colorectal cancer cells through activation of p53. Cancer Lett 301: 185-192, 2011.

46. Choi S, Oh JY and Kim SJ: Ginsenoside Rh2 induces Bcl-2 family proteins-mediated apoptosis in vitro and in xenografts in vivo models. J Cell Biochem 112: 330-340, 2011.

47. Kim HE, Oh JH, Lee SK and Oh YJ: Ginsenoside RH-2 induces apoptotic cell death in rat C6 glioma via a reactive oxygen- and caspase-dependent but Bcl-X(L)-independent pathway. Life Sci 65: PL33-PL40, 1999.

48. Kim YS, Jin SH, Lee YH, Kim SI and Park JD: Ginsenoside $\mathrm{Rh} 2$ induces apoptosis independently of Bcl-2, Bcl-xL, or Bax in C6Bu-1 cells. Arch Pharm Res 22: 448-453, 1999.

49. Park JA, Lee KY, Oh YJ, Kim KW and Lee SK: Activation of caspase-3 protease via a Bcl-2-insensitive pathway during the process of ginsenoside Rh2-induced apoptosis. Cancer Lett 121: 73-81, 1997

50. Popovich DG and Kitts DD: Ginsenosides 20(S)-protopanaxadiol and $\mathrm{Rh} 2$ reduce cell proliferation and increase sub-G1 cells in two cultured intestinal cell lines, Int-407 and Caco-2. Can J Physiol Pharmacol 82: 183-190, 2004

51. Oh M, Choi YH, Choi S, et al: Anti-proliferating effects of ginsenoside $\mathrm{Rh} 2$ on MCF-7 human breast cancer cells. Int J Oncol 14: 869-875, 1999.

52. Cheng CC, Yang SM, Huang CY, Chen JC, Chang WM and Hsu SL: Molecular mechanisms of ginsenoside Rh2-mediated G1 growth arrest and apoptosis in human lung adenocarcinoma A549 cells. Cancer Chemother Pharmacol 55: 531-540, 2005.

53. Oh JI, Chun KH, Joo SH, Oh YT and Lee SK: Caspase-3dependent protein kinase $\mathrm{C}$ delta activity is required for the progression of Ginsenoside-Rh2-induced apoptosis in SK-HEP-1 cells. Cancer Lett 230: 228-238, 2005. 
54. Ham YM, Lim JH, Na HK, et al: Ginsenoside-Rh2-induced mitochondrial depolarization and apoptosis are associated with reactive oxygen species- and $\mathrm{Ca}^{2+}$-mediated c-Jun NH2-terminal kinase 1 activation in HeLa cells. J Pharmacol Exp Ther 319: 1276-1285, 2006.

55. Park EK, Lee EJ, Lee SH, et al: Induction of apoptosis by the ginsenoside $\mathrm{Rh} 2$ by internalization of lipid rafts and caveolae and inactivation of Akt. Br J Pharmacol 160: 1212-1223, 2010.

56. Yi JS, Choo HJ, Cho BR, et al: Ginsenoside Rh2 induces ligandindependent Fas activation via lipid raft disruption. Biochem Biophys Res Commun 385: 154-159, 2009.

57. An IS, An S, Kwon KJ, Kim YJ and Bae S: Ginsenoside Rh2 mediates changes in the microRNA expression profile of human non-small cell lung cancer A549 cells. Oncol Rep 29: 523-528, 2013.

58. Wu N, Wu GC, Hu R, Li M and Feng H: Ginsenoside Rh2 inhibits glioma cell proliferation by targeting microRNA-128. Acta Pharmacol Sin 32: 345-353, 2011.

59. Park TY, Park MH, Shin WC, et al: Anti-metastatic potential of ginsenoside Rp1, a novel ginsenoside derivative. Biol Pharm Bull 31: 1802-1805, 2008.

60. Kang JH, Song KH, Woo JK, et al: Ginsenoside Rp1 from Panax ginseng exhibits anti-cancer activity by down-regulation of the IGF-1R/Akt pathway in breast cancer cells. Plant Foods Hum Nutr 66: 298-305, 2011.

61. Kumar A, Kumar M, Park TY, et al: Molecular mechanisms of ginsenoside Rp1-mediated growth arrest and apoptosis. Int J Mol Med 24: 381-386, 2009

62. Kim JS, Joo EJ, Chun J, et al: Induction of apoptosis by ginsenoside Rk1 in SK-MEL-2-human melanoma. Arch Pharm Res 35 717-722, 2012.

63. Kim YJ, Kwon HC, Ko H, et al: Anti-tumor activity of the ginsenoside Rk1 in human hepatocellular carcinoma cells through inhibition of telomerase activity and induction of apoptosis. Biol Pharm Bull 31: 826-830, 2008.

64. Kim SE, Lee YH, Park JH and Lee SK: Ginsenoside-Rs3, a new diol-type ginseng saponin, selectively elevates protein levels of p53 and p21WAF1 leading to induction of apoptosis in SK-HEP-1 cells. Anticancer Res 19: 487-491, 1999.

65. Wang W, Wang H, Rayburn ER, Zhao Y, Hill DL and Zhang R 20(S)-25-methoxyl-dammarane-3beta, 12beta, 20-triol, a novel natural product for prostate cancer therapy: activity in vitro and in vivo and mechanisms of action. Br J Cancer 98: 792-802, 2008.

66. Park S, Lee HJ, Jeong SJ, et al: Inhibition of JAK1/STAT3 signaling mediates compound K-induced apoptosis in human multiple myeloma U266 cells. Food Chem Toxicol 49: 1367-1372, 2011.

67. Sathishkumar N, Sathiyamoorthy S, Ramya M, Yang DU, Lee HN and Yang DC: Molecular docking studies of anti-apoptotic BCL-2, BCL-XL, and MCL-1 proteins with ginsenosides from Panax ginseng. J Enzyme Inhib Med Chem 27: 685-692, 2012.

68. Liu J, Shimizu K, Yu H, Zhang C, Jin F and Kondo R: Stereospecificity of hydroxyl group at C-20 in antiproliferative action of ginsenoside $\mathrm{Rh} 2$ on prostate cancer cells. Fitoterapia 81 : 902-905, 2010

69. Dong H, Bai LP, Wong VK, et al: The in vitro structure-related anti-cancer activity of ginsenosides and their derivatives. Molecules 16: 10619-10630, 2011.

70. Chen QJ, Zhang MZ and Wang LX: Gensenoside Rg3 inhibits hypoxia-induced VEGF expression in human cancer cells. Cell Physiol Biochem 26: 849-858, 2010.

71. Yue PY, Wong DY, Wu PK, et al: The angiosuppressive effects of 20(R)- ginsenoside Rg3. Biochem Pharmacol 72: 437-445, 2006.

72. Zhang Q, Kang X, Yang B, Wang J and Yang F: Antiangiogenic effect of capecitabine combined with ginsenoside $\mathrm{Rg} 3$ on breast cancer in mice. Cancer Biother Radiopharm 23: 647-653, 2008

73. Xu TM, Xin Y, Cui MH, Jiang X and Gu LP: Inhibitory effect of ginsenoside $\mathrm{Rg} 3$ combined with cyclophosphamide on growth and angiogenesis of ovarian cancer. Chin Med J (Engl) 120: 584-588, 2007.

74. Zhang Q, Kang X and Zhao W: Antiangiogenic effect of low-dose cyclophosphamide combined with ginsenoside $\operatorname{Rg} 3$ on Lewis lung carcinoma. Biochem Biophys Res Commun 342: 824-828, 2006 .
75. Kim JW, Jung SY, Kwon YH, et al: Ginsenoside Rg3 attenuates tumor angiogenesis via inhibiting bioactivities of endothelial progenitor cells. Cancer Biol Ther 13: 504-515, 2012.

76. Sato K, Mochizuki M, Saiki I, Yoo YC, Samukawa K and Azuma I: Inhibition of tumor angiogenesis and metastasis by a saponin of Panax ginseng, ginsenoside-Rb2. Biol Pharm Bull 17: 635-639, 1994

77. Jeong A, Lee HJ, Jeong SJ, Lee EO, Bae $\mathrm{H}$ and $\mathrm{Kim} \mathrm{SH}$ Compound $\mathrm{K}$ inhibits basic fibroblast growth factor-induced angiogenesis via regulation of p38 mitogen activated protein kinase and AKT in human umbilical vein endothelial cells. Biol Pharm Bull 33: 945-950, 2010.

78. Pan XY, Guo H, Han J, et al: Ginsenoside Rg3 attenuates cell migration via inhibition of aquaporin 1 expression in PC-3M prostate cancer cells. Eur J Pharmacol 683: 27-34, 2012.

79. Mochizuki M, Yoo YC, Matsuzawa K, et al: Inhibitory effect of tumor metastasis in mice by saponins, ginsenoside-Rb2, 20(R)and 20(S)-ginsenoside-Rg3, of red ginseng. Biol Pharm Bull 18: 1197-1202, 1995

80. Xu TM, Cui MH, Xin Y, et al: Inhibitory effect of ginsenoside $\mathrm{Rg} 3$ on ovarian cancer metastasis. Chin Med J (Engl) 121: 1394-1397, 2008

81. Chen XP, Qian LL, Jiang H and Chen JH: Ginsenoside Rg3 inhibits CXCR4 expression and related migrations in a breast cancer cell line. Int J Clin Oncol 16: 519-523, 2011.

82. Iishi $\mathrm{H}$, Tatsuta $\mathrm{M}$, Baba M, et al: Inhibition by ginsenoside Rg3 of bombesin-enhanced peritoneal metastasis of intestinal adenocarcinomas induced by azoxymethane in Wistar rats. Clin Exp Metastasis 15: 603-611, 1997.

83. Shinkai K, Akedo H, Mukai M, et al: Inhibition of in vitro tumor cell invasion by ginsenoside Rg3. Jpn J Cancer Res 87: 357-362, 1996.

84. Yoon JH, Choi YJ and Lee SG: Ginsenoside Rh1 suppresses matrix metalloproteinase-1 expression through inhibition of activator protein-1 and mitogen-activated protein kinase signaling pathway in human hepatocellular carcinoma cells. Eur J Pharmacol 679: 24-33, 2012.

85. Yoon JH, Choi YJ, Cha SW and Lee SG: Anti-metastatic effects of ginsenoside Rd via inactivation of MAPK signaling and induction of focal adhesion formation. Phytomedicine 19: 284-292, 2012

86. Kim SY, Kim DH, Han SJ, Hyun JW and Kim HS: Repression of matrix metalloproteinase gene expression by ginsenoside $\mathrm{Rh} 2$ in human astroglioma cells. Biochem Pharmacol 74: 1642-1651, 2007.

87. Ming Y, Chen Z, Chen L, et al: Ginsenoside compound K attenuates metastatic growth of hepatocellular carcinoma, which is associated with the translocation of nuclear factor-kappaB p65 and reduction of matrix metalloproteinase-2/9. Planta Med 77: 428-433, 2011.

88. Hasegawa $\mathrm{H}$ and Uchiyama $\mathrm{M}$ : Antimetastatic efficacy of orally administered ginsenoside Rb1 in dependence on intestinal bacterial hydrolyzing potential and significance of treatment with an active bacterial metabolite. Planta Med 64: 696-700, 1998.

89. Choo MK, Sakurai H, Kim DH and Saiki I: A ginseng saponin metabolite suppresses tumor necrosis factor- $\alpha$-promoted metastasis by suppressing nuclear factor- $\kappa \mathrm{B}$ signaling in murine colon cancer cells. Oncol Rep 19: 595-600, 2008.

90. Kim SM, Lee SY, Yuk DY, et al: Inhibition of NF-kappaB by ginsenoside Rg3 enhances the susceptibility of colon cancer cells to docetaxel. Arch Pharm Res 32: 755-765, 2009.

91. Kim SM, Lee SY, Cho JS, et al: Combination of ginsenoside $\mathrm{Rg} 3$ with docetaxel enhances the susceptibility of prostate cancer cells via inhibition of NF-kappaB. Eur J Pharmacol 631: 1-9, 2010.

92. Musende AG, Eberding A, Jia W, Ramsay E, Bally MB and Guns ET: Rh2 or its aglycone aPPD in combination with docetaxel for treatment of prostate cancer. Prostate 70: 1437-1447, 2010

93. Yang LQ, Wang B, Gan H, et al: Enhanced oral bioavailability and anti-tumour effect of paclitaxel by 20(s)-ginsenoside $\mathrm{Rg} 3$ in vivo. Biopharm Drug Dispos 33: 425-436, 2012.

94. Pokharel YR, Kim ND, Han HK, Oh WK and Kang KW: Increased ubiquitination of multidrug resistance 1 by ginsenoside Rd. Nutr Cancer 62: 252-259, 2010.

95. Lee CK, Park KK, Chung AS and Chung WY: Ginsenoside Rg3 enhances the chemosensitivity of tumors to cisplatin by reducing the basal level of nuclear factor erythroid 2-related factor 2-mediated heme oxygenase-1/NAD $(\mathrm{P}) \mathrm{H}$ quinone oxidoreductase-1 and prevents normal tissue damage by scavenging cisplatin-induced intracellular reactive oxygen species. Food Chem Toxicol 50: 2565-2574, 2012. 
96. Kikuchi Y, Sasa H, Kita T, Hirata J, Tode T and Nagata I: Inhibition of human ovarian cancer cell proliferation in vitro by ginsenoside $\mathrm{Rh} 2$ and adjuvant effects to cisplatin in vivo. Anticancer Drugs 2: 63-67, 1991.

97. Xie X, Eberding A, Madera C, et al: Rh2 synergistically enhances paclitaxel or mitoxantrone in prostate cancer models. J Urol 175: 1926-1931, 2006.

98. Jia WW, Bu X, Philips D, et al: Rh2, a compound extracted from ginseng, hypersensitizes multidrug-resistant tumor cells to chemotherapy. Can J Physiol Pharmacol 82: 431-437, 2004.

99. Chae S, Kang KA, Chang WY, et al: Effect of compound K, a metabolite of ginseng saponin, combined with gamma-ray radiation in human lung cancer cells in vitro and in vivo. J Agric Food Chem 57: 5777-5782, 2009.

100. Park SA, Kim EH, Na HK and Surh YJ: KG-135 inhibits COX-2 expression by blocking the activation of JNK and AP-1 in phorbol ester-stimulated human breast epithelial cells. Ann NY Acad Sci 1095: 545-553, 2007.

101. Yoo JH, Kwon HC, Kim YJ, Park JH and Yang HO: KG-135, enriched with selected ginsenosides, inhibits the proliferation of human prostate cancer cells in culture and inhibits xenograft growth in athymic mice. Cancer Lett 289: 99-110, 2010.
102. Lee WH, Choi JS, Kim HY, et al: Potentiation of etoposideinduced apoptosis in HeLa cells by co-treatment with KG-135, a quality-controlled standardized ginsenoside formulation. Cancer Lett 294: 74-81, 2010.

103. Tatsuka M, Maeda M and Ota T: Anticarcinogenic effect and enhancement of metastatic potential of BALB/c 3T3 cells by ginsenoside Rh(2). Jpn J Cancer Res 92: 1184-1189, 2001

104. Jeong HG, Pokharel YR, Han EH and Kang KW: Induction of cyclooxygenase -2 by ginsenoside Rd via activation of CCAATenhancer binding proteins and cyclic AMP response binding protein. Biochem Biophys Res Commun 359: 51-56, 2007.

105. Kim JH, Park CY and Lee SJ: Effects of sun ginseng on subjective quality of life in cancer patients: a double-blind, placebo-controlled pilot trial. J Clin Pharm Ther 31: 331-334, 2006.

106. Lu P, Su W, Miao ZH, Niu HR, Liu J and Hua QL: Effect and mechanism of ginsenoside Rg3 on postoperative life span of patients with non-small cell lung cancer. Chin J Integr Med 14: 33-36, 2008 